\title{
Prospecção fitoquímica e avaliação do potencial antioxidante de Cnidoscolus phyllacanthus (müll. Arg.) Pax \& k.hoffm. Oriundo de apodi - RN
}

MORAIS, N.R.L. ${ }^{1}$; OLIVEIRA NETO, F.B. ${ }^{1}$ MELO, A.R.. ${ }^{1}$ BERTINI, L.M. ${ }^{1}$; SILVA, F.F.M. ${ }^{1}$; ALVES, L.A. ${ }^{1 *}$ 'Instituto Federal do Rio Grande do Norte (IFRN) - Campus Apodi. Sítio Lagoa do Clementino, nº 999, CEP: 59700-971, Apodi-RN - Brasil. *Autor para correspondência: leonardo.alcantara@ifrn.edu.br

\begin{abstract}
RESUMO: As principais propriedades encontradas nas plantas com benefícios a saúde são, muitas vezes, resultados dos metabólitos secundários encontrados em seus extratos. A espécie Cnidoscolus phyllacanthus, popularmente conhecida como faveleira ou favela, conta com diversos relatos na medicina popular, tais como: cicatrizante, analgésico, anti-inflamatório, antibiótico e diurético. O objetivo deste trabalho foi avaliar de forma qualitativa e quantitativa os metabólitos secundários presentes nos extratos da espécie C. phyllacanthus oriunda do Nordeste Brasileiro bem como avaliar a atividade antioxidante de seus extratos. Diversos grupos de metabólitos foram determinados em seus galhos, raízes e folhas, tais como: taninos, antocianinas e alcaloides. Em relação à atividade antioxidante, as folhas da faveleira tiveram destaque, apresentado $\mathrm{Cl}_{50}$ de $58,3 \mathrm{ppm}$, semelhante ao da vitamina $\mathrm{C}(43,0 \mathrm{ppm})$ utilizado como padrão positivo. O estudo serve como aporte inicial sobre o conhecimento da viabilidade de utilização dessa planta para fins medicinais.
\end{abstract}

Palavras-chave: Espécies nativas; quantificação de metabólitos; radical DPPH.

\begin{abstract}
Phytochemical screening and antioxidant potencial evaluation of Cnidoscolus phyllacanthus (Müll. Arg.) Pax \& K.Hoffm from Apodi - RN. Main health benefits properties found in plants are results of secondary metabolites found in their extracts. In this sense, there is the Cnidoscolus phyllacanthus species, popularly known as faveleira or favela, with several reports in tradicional medicine, such as healing, analgesic, anti-inflammatory, antibiotic and diuretic. This study aims to evaluate qualitatively and quantitatively the secondary metabolites present in Cnidoscolus phyllacanthus extracts from Brazilian Northeast and their antioxidant activity. Several metabolites were determined from its branches, roots and leaves, such as tannins, alkaloids and anthocyanins. In antioxidant activity, faveleira leaves had highlighted, presenting $\mathrm{IC}_{50}$ of $58.3 \mathrm{ppm}$, similar to vitamin $\mathrm{C}(43.0 \mathrm{ppm})$ used as a positive standard. This study is a contribution for the knowledge about the use of this plant for medicinal purposes.
\end{abstract}

Keywords: Native species; metabolites quantification; DPPH radical.

\section{INTRODUÇÃO}

O uso de medicamentos obtidos a partir de fontes vegetais é antigo, mas tem crescido nos últimos anos a procura por produtos naturais com atividades farmacológicas que trazem benefícios para a humanidade. Sabe-se que a maioria dos fármacos de origem natural, utilizados atualmente, são oriundos da chamada medicina tradicional ou popular o que demonstra que as substâncias de origem vegetal têm papel essencial na obtenção de medicamentos e que, partindo do conhecimento popular, bons resultados podem ser obtidos (Salomé, 2007).

As plantas são fontes naturais de uma infinidade de substâncias químicas que são biossintetizadas com várias finalidades, entre elas, protegê-las contra predadores ou atrair polinizadores (Souza et al., 2003). Os metabólitos secundários encontrados nessas plantas têm como função a defesa contra herbívoros e microrganismos, a proteção contra os raios UV (ultravioleta), a atração de polinizadores ou animais dispersores de sementes bem como produção de substâncias alelopáticas, como nutriente, dependendo de cada caso específico (Simões et al., 2010).

A caatinga é um bioma com grande diversidade que, sendo exclusivamente Brasileiro,

Recebido para publicação em 30/03/2015 
apresenta um patrimônio biológico que, em muitos casos, não pode ser encontrado em nenhum outro lugar do planeta, apresentando uma variedade de plantas medicinais tradicionalmente utilizadas em tratamentos caseiros. Nela é encontrada a espécie Cnidoscolus phyllacanthus (Müll. Arg.) Pax \& L. Hoffm., popularmente conhecida como faveleira ou favela, uma planta pertencente à família Euphorbiaceae, decídua, heliófila, pioneira e endêmica da caatinga nordestina, que ocorre abundantemente em diversos Estados do Brasil, com destaque na Paraíba, Pernambuco, Bahia, Piauí, Rio Grande do Norte, Ceará, Sergipe e Alagoas (Marques, 2007).

Pesquisas realizadas em Comunidades do Semiárido paraibano relatam uma intensa utilização da faveleira como planta medicinal, seguido do uso na alimentação animal, enquanto que, na alimentação humana, há pouco conhecimento de suas potencialidades. Na medicina popular são relatadas, principalmente, as propriedades: cicatrizante, analgésica, anti-inflamatória, antibiótica e diurética (Nóbrega, 2001). Lacerda (2011) destaca o uso de C. phyllacanthus como inibidora de bactérias patogênicas, comprovando sua atividade antimicrobiana. O trabalho constitui fonte de perspectivas para a obtenção de antibióticos tópicos a partir da espécie.

Dentre as diversas propriedades apresentadas pelos metabólitos secundários biossintetizados pelos vegetais, a atividade antioxidante, exibida por muitas plantas de uso comum na medicina tradicional, apresenta destaque. Isso devido ao fato dos antioxidantes, que são substâncias que em pequenas concentrações, em comparação ao substrato oxidável, retardam ou previnem significativamente o início ou a propagação da cadeia de reações de oxidação. Estes compostos inibem não só a peroxidação dos lipídios, mas também, a oxidação de outras moléculas, como proteínas e DNA (Halliwell et al., 1995). Desta forma, o presente trabalho teve como objetivo principal avaliar os extratos de Cnidoscolus phyllacanthus (faveleira) oriundo do oeste potiguar visando a identificação das classes de metabólitos assim como avaliar o potencial antioxidante apresentado nos seus respectivos extratos. Além disso, pretende-se colaborar para um maior conhecimento científico da flora Brasileira, que é uma das maiores e mais diversificadas do mundo.

\section{MATERIAIS E MÉTODOS}

Todas as análises espectrométricas foram realizadas em aparelho espectrofotômetro UV-Vis marca TEN-KA T-2000. A matéria-prima utilizada na obtenção dos extratos de $C$. phyllacanthus (faveleira) foi cultivada e obtida no Instituto Federal de Educação, Ciência e Tecnologia do Rio Grande do Norte (IFRN) - Campus Apodi (053' $34^{\prime \prime} \mathrm{S}$, $37^{\circ} 48^{\prime} 34^{\prime \prime}$ O). O material $(500,0 \mathrm{~g})$ foi previamente separado por folhas, galhos e raízes, triturado e deixado ao ar livre para perda de umidade. O mesmo foi extraído exaustiva e sucessivamente em hexano, etanol e água puros e secos em evaporador rotativo a pressão reduzida para obtenção de seus extratos.

Como análise preliminar, foram realizadas uma série de testes qualitativos propostos por Matos (1997) com intuito de identificar os grupos de metabólitos secundários presentes nos extratos da faveleira. No processo foram avaliados a presença de: fenóis e taninos; antocianinas, antocianidinas e flavonóides; leucoantocianidinas, catequinas e flavanonas; flavonóis, flavanonas, flavanonóis e xantonas; esteróides e triterpenóides.

A determinação de fenóis totais (FT) de cada extrato foi realizada pelo método de FolinCicalteau descrita por Bonoli et al. (2004). O teor de FT foi determinado por interpolação da absorbância das amostras contra uma curva de calibração obtida com padrões de ácido gálico (10 a $350 \mu \mathrm{g} / \mathrm{mL}$ ) e expressos como mg de EAG (equivalência de ácido gálico) por g de extrato.

A extração e análise de antocianinas (ANT) foram realizadas de acordo com Teixeira et al. (2008). A Absorbância foi avaliada em espectrofotômetro, efetuando-se leituras em comprimento de onda de $535 \mathrm{~nm}$. Os valores de absorbância (DO) foram contrastados com os valores dos brancos [Solução Etanol-HCL 1,5N (85:15)]. O conteúdo total de antocianinas foi expresso em $\mathrm{mg}$ de antocianinas $/ 100 \mathrm{~g}$ da fração da amostra analisada.

A determinação dos teores de Alcalóides totais (AT) foi realizada de acordo com Lúcio et al. (2002) com modificações. Cinco gramas (g) de material vegetal (folhas, galhos e raiz) foram extraídos com diclorometano, com agitação por 24 horas. Em seguida, adicionou-se hidróxido de amônio $5 \%$ e agitou-se por $30 \mathrm{~min}$. A mistura foi filtrada em uma solução de ácido sulfúrico a $5 \%$. Após agitação, a fase orgânica foi transferida para uma solução de ácido sulfúrico $2,5 \%$. As fases aquosas ácidas foram reunidas e extraídas com diclorometano. A fase ácida foi neutralizada com hidróxido de amônio ( $\mathrm{pH} \sim 9$ 9,0). A fase orgânica foi evaporada em placa aquecedora. O resíduo da evaporação foi resfriado, adicionado de ácido sulfúrico $0,05 \mathrm{~N}$, indicador vermelho de metila e titulado com hidróxido de sódio $0,05 \mathrm{~mol} / \mathrm{L}$.

A avaliação do teor de taninos (TAN) foi realizada conforme metodologia proposta por Broadhurst \& Jones (1978), empregando-se a catequina como padrão. A absorbância foi medida 
em espectrofotômetro a $500 \mathrm{~nm}$. O teor de taninos foi obtido a partir da plotagem do valor observado em curva de calibração previamente realizada utilizando catequina.

A avaliação da capacidade antioxidante dos extratos da C. phyllacanthus, foi feito através do método de captura dos radicais livres DPPH (2,2-difenil-1-picril-hidrazil) descrito por Almeida et al. (2010). Cada extrato foi pesado e diluído a fim de se obter soluções em diferentes concentrações (1000, 500, 100, 50, 40 e 20 ppm). Após diluída, uma alíquota de $1 \mathrm{~mL}$ de cada concentração foi disposta em tubos de ensaio, em ambiente escuro, juntamente com $1 \mathrm{~mL}$ de uma solução de DPPH 60 umolar. Após decorrido os 30 minutos, foi feito a leitura da absorbância das amostras em espectrofotômetro nos comprimentos de onda de $520 \mathrm{~nm}$, tendo como branco o solvente utilizado para a preparação das soluções. Também foi realizada a leitura de uma solução contendo $1 \mathrm{~mL}$ do solvente e $1 \mathrm{~mL}$ da solução DPPH, previamente preparado. Após a leitura das absorbâncias das amostras foi feito um gráfico utilizando-se um software Oringin 7.0 , utilizando os valores da porcentagem de inibição de cada concentração, com a finalidade de se verificar a linearidade dos resultados obtidos, e calcular os valores de $\mathrm{Cl}_{50}$.

Os resultados apresentados nas análises de fenóis, antocianinas, taninos e atividade antioxidante dos extratos correspondem a média de três repetições \pm desvio padrão.

\section{RESULTADOS E DISCUSSÃO}

Os rendimentos dos extratos secos foram obtidos a partir das relações destes com as massas dos materiais previamente pesados, conforme apresentado na Tabela 1.

Avaliação fitoquímica dos extratos da faveleira possibilitou a análise qualitativa dos seus metabólitos secundários (Tabela 2). A partir dos resultados obtidos, pode-se evidenciar nos extratos em hexano das folhas e galhos a presença de flavonoides do tipo flavonas, flavonóis e xantonas bem como triterpenóides pentacíclicos livres em suas raízes. Observou-se novamente a presença de flavonas, flavonóis e xantonas em suas folhas, agora no extrato em etanol. Além disso, foi possível a determinação de saponinas nos extratos em etanol das raízes e catequinas e flavanonas nos galhos. Já nos extratos em água, as folhas apresentaram testes positivos nas análises de fenóis, flavonoides e xantonas e os galhos para fenóis, flavonoides e xantonas e saponinas.

Gomes et al. (2014) relata a presença de diversas outras classes de metabólitos secundários em Cnidoscolus quercifolius, sinonímia botânica de C. phyllancanthus, obtida na cidade de Petrolina, como cumarinas, flavonoides, mononoterpenos, diterpenos, entre outros. No referido estudo os autores se limitaram a avaliar apenas os extratos em etanol das cascas e folhas do vegetal.

Compostos fenólicos são substâncias amplamente distribuídas no reino vegetal, em particular nas frutas e em outros vegetais. São conjuntos heterogêneos que apresentam em sua

TABELA 1. Teores dos extratos secos das folhas, raízes e galhos da faveleira

\begin{tabular}{cccc}
\hline Material vegetal & Extrato em hexano & Extrato em etanol & Extrato em água \\
\hline Folhas & $7,63 \%$ & $15,78 \%$ & $9,44 \%$ \\
Raízes & $0,25 \%$ & $2,33 \%$ & $1,87 \%$ \\
Galhos & $0,42 \%$ & $4,32 \%$ & $2,44 \%$ \\
\hline
\end{tabular}

TABELA 2. Prospecção fitoquímica dos extratos das folhas, raízes e galhos da faveleira

\begin{tabular}{|c|c|c|c|c|c|c|c|c|c|}
\hline Testes & EHF & EHR & EHG & EEF & EER & EEG & EAF & EAR & EAG \\
\hline Fenóis e taninos & - & - & - & - & - & - & - & - & - \\
\hline Antocianinas, antocianidinas e flavonoides & $+\mathrm{a}$ & - & $+a$ & $+a$ & - & - & - & - & - \\
\hline Leucoantocianidinas, catequinas e flavonas & - & - & - & - & - & $+c+d$ & - & -- & -- \\
\hline Fenóis, flavonoides e xantonas & - & - & - & - & - & - & + & - & + \\
\hline Esteróides e triterpenóides & - & $+\mathrm{b}$ & - & - & - & - & - & - & - \\
\hline Saponinas & - & - & - & - & + & - & - & - & + \\
\hline
\end{tabular}

EHF: Extrato em hexano das folhas; EHR: Extrato em hexano das raízes; EHG: extrato em hexano dos galhos; EEF: Extrato em etanol das folhas; EER: Extrato em etanol das raízes; EEG: extrato em etanol dos galhos; EAF: Extrato em água das folhas; EAR: Extrato em água

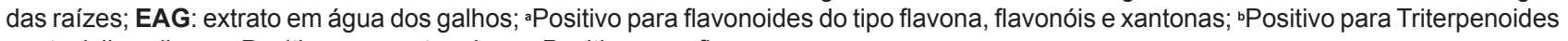
pentaciclicas livres; 'Positivo para catequinas; dPositivo para flavononas 
estrutura vários grupos benzênicos característicos, substituídos por grupamentos hidroxilas. Devido à sua ampla variedade, enquadram-se em diversas categorias, como fenóis simples, ácidos fenólicos, entre outros (Naczk \& Shahidi, 2004). A partir dos dados obtidos por meio dos testes fenólicos de C. phyllacanthus pode-se observar que o extrato em hexano e etanol das raízes foram os que apresentaram os menores teores, com valores de 9,1 mg EAG/g extrato bruto e 20,5 mg EAG/g extrato bruto, respectivamente. $O$ extrato em etanol das folhas apresentou o melhor resultado com teor de 135,8 $\mathrm{mg}$ EAG/g extrato bruto seguido pelo seu extrato em água, com $81,4 \mathrm{mg}$ EAG/g extrato bruto (Tabela 3). Os resultados mostram que estes extratos são boas fontes de fenóis, compostos com inúmeras atividades biológicas e farmacológicas amplamente descritas na literatura.

A partir da análise dos testes de quantificação de antocianinas (Tabela 3), quando comparados com os realizados de Teixeira et al. (2008) em diferentes vegetais com teores de antocianinas variando de 12,67 mg Ant/100g amostra (Romã) a 492,74 mg Ant/100g amostra (Jabuticaba), podese concluir que a faveleira apresenta uma baixa concentração de antocianinas. Apesar disso, as folhas apresentaram o maior teor de ANT, de 0,12 $\mathrm{mg}$ Ant $/ 100 \mathrm{~g}$ amostra. O valor é semelhante ao obtido nas espécies mangerioba do Pará (Senna alata) e mini-girassol (Tithonia diversifolia) com valores de 0,16 mg Ant/100g e 0,22 mg Ant/100g, respectivamente (Brilhante, 2013). Esse estudo se faz relevante, pois comprovou a existência desse grupo de substâncias específica no material analisado.

Através do estudo quantitativo de alcalóides totais da Cnidoscolus phyllacanthus (Tabela 3) pode-se observar que as folhas foram os que apresentaram a menor porcentagem de alcalóides, apenas com $0,27 \%$ no total. Obtiveram destaque os galhos e as raízes da faveleira com $0,45 \%$ e $0,62 \%$, respectivamente. O resultado mostra que a partes da faveleira, como os galhos e as raízes são boas fontes de alcalóides, compostos com inúmeras atividades biológicas e farmacológicas amplamente descritas na literatura. Vale ressaltar que a raiz da faveleira apresentou teor de alcalóides superior aos descritos por Lúcio et al. (2002) em seu estudo utilizando Pilocarpus pennatifolius (com máximo de $0,53 \%$ ), reconhecida pela presença de diversos alcaloides, dentre eles a pilocarpina, utilizada no tratamento de glaucoma.

A análise do teor de taninos em $C$. phyllancantus demonstrou uma alta concentração em suas raízes, com 72,0 ppm, seguido dos galhos, 59,0 ppm, e das folhas, 22,0 ppm (Tabela 3). Na literatura os testes para a quantificação de taninos são realizados, muitas vezes, a partir de extratos do caule das plantas visto que neste pois estes, principalmente os taninos condensados, são associados pela alta concentração. No caso da faveleira pode-se observar que a maior concentração de taninos se encontra nas raízes. Esse fato pode servir de questionamento para que sejam feitas pesquisas sobre a quantificação de taninos presentes em outras espécies vegetais, podendo assim permitir a descoberta de novas fontes desse grupo de substâncias.

Compostos com ação antioxidante podem ser definidos como aqueles capazes de retardar ou inibir a oxidação de substratos oxidáveis, podendo estes ser enzimáticos ou não enzimáticos, tais como: $\alpha$-tocoferol (vitamina E), $\beta$-caroteno, ascorbato (vitamina C) e os compostos fenólicos (flavonóides) (Sousa et al., 2007). Os antioxidantes são agentes responsáveis pela inibição e redução das lesões causadas pelos radicais livres nas células (Morais, 2009).

A partir dos resultados obtidos nos testes antioxidantes dos extratos da faveleira (Tabela 4), pode-se concluir que os mesmos apresentaram uma capacidade antioxidante relativamente baixa com valores altos de $\mathrm{Cl}_{50}$ quando comparados aos padrões positivos. Deve-se destacar, dentre estes, o extrato em hexano das folhas que apresentou uma relevante atividade antioxidante, com valor de $\mathrm{Cl}_{50}$ (58,3 ppm) próximo ao obtido com o padrão positivo vitamina C (43,0 ppm).

\section{CONCLUSÃO}

As análises realizadas com diferentes órgãos de C. phyllacanthus (faveleira) foram capazes de relevar diversos metabólitos secundários presentes na espécie. Esses grupos de compostos podem ser os responsáveis por inúmeras das

TABELA 3. Teores de metabólitos nos extratos das folhas, raízes e galhos da faveleira

\begin{tabular}{|c|c|c|c|c|c|c|}
\hline \multirow{2}{*}{$\begin{array}{l}\text { Material } \\
\text { vegetal }\end{array}$} & \multicolumn{3}{|c|}{ Teor de fenóis totais (mg EAG/g ext. bruto) } & \multirow{2}{*}{$\begin{array}{c}\text { Antocianinas } \\
\text { (mg Ant/100g amostra) }\end{array}$} & \multirow{2}{*}{$\begin{array}{l}\text { Alcalóides } \\
\text { totais (\%) }\end{array}$} & \multirow{2}{*}{ Taninos (ppm) } \\
\hline & Hexano & Etanol & Água & & & \\
\hline Folhas & $\pm 4,2$ & $135,8 \pm 1,4$ & 3 & $0,12 \pm 5,2 \cdot 10^{-4}$ & 0,27 & \\
\hline Galhos & -- & $22,2 \pm 5,0.10^{-2}$ & $38,5 \pm 1,4.10^{-3}$ & $7,6 \times 10$ & 0,45 & $10^{-3}$ \\
\hline Raiz & $9,1 \pm 4,5.10^{-6}$ & $20,5 \pm 2,1.10^{-3}$ & -- & $1,0 \times 10^{-3} \pm 2,3.10^{-5}$ & 0,62 & $72,0 \pm 4,5.10^{-3}$ \\
\hline
\end{tabular}

(--) Fora do limite de detecção 
TABELA 4. Resultados dos testes antioxidantes dos extratos da faveleira

\begin{tabular}{lccc}
\hline Material & \multicolumn{3}{c}{ Valores de $\mathbf{C l}_{50}(\mathbf{p p m})$} \\
\cline { 2 - 4 } & Hexano & Etanol & Água \\
\hline Folhas & $58,3 \pm 9,2$ & $245,7 \pm 2,5$ & $230,0 \pm 1,2$ \\
Galhos & $382,5 \pm 18,4$ & $362,6 \pm 0,9$ & NAA \\
Raízes & $\mathrm{NAA}$ & $203,6 \pm 0,6$ & $\mathrm{NAA}$ \\
\hline Vitamina C & & 43,0 & \\
Trolox & & 4,0 & \\
\hline
\end{tabular}

NAA = não apresentou atividade

propriedades terapêuticas relatadas atribuídas à planta. Destaca-se ainda que o presente estudo identificou um expressivo potencial antioxidante apenas nas folhas do vegetal, análise esta que pode servir de base para estudos futuros que busquem novas fontes naturais de compostos com esta propriedade.

\section{AGRADECIMENTOS}

Os autores agradecem ao CNPq e FUNCERN pela liberação de bolsas de pesquisa e recurso financeiro e ao prof. Dr. Renato Dantas Alencar, engenheiro agrônomo, pela doação do material vegetal estudado.

\section{REFERÊNCIAS}

ALMEIDA, M.C.S. et al. Flavonoides e outras substâncias de Lippia sidoides e suas atividades antioxidantes. Química Nova, v. 33, n. 9, p. 187781, 2010.

BONOLI, M. et al. Antioxidant phenols in barley (Hordeum vulgare L.) flour: comparative spectrophotometric study among extraction methods of free and bound phenolic compounds. Journal of Agricultural and Food Chemistry, v. 52, p. 5195-00, 2004.

BRILHANTE, S.E.T. Determinação do teor de antocianinas e sua influência na capacidade indicadora de $\mathrm{pH}$ em extratos de flores do Rio Grande do Norte. 2013. 37p. Trabalho de Conclusão de Curso (Graduação - Área de Concentração em Química). Instituto Federal do Rio Grande do Norte, Apodi.

BROADHURST, R.B.; JONES, W.T.; Analysis of condensed tannins using acidified vanillin. Journal of Science of Food and Agriculture, v. 29, n. 9, p. 788-94, 1978.

GOMES, L.M.A. et al. Phytochemical screening and anti-inflammatory activity of Cnidoscolus quercifolius (Euphorbiaceae) in mice. Pharmacognosy Research, v. 6, n. 4, p. 34549, 2014.
HALLIWELL, B. et al. The characterization of antioxidants. Food and Chemical Toxicology, v. 33, n. 7, p. 601-17, 1995.

LACERDA, S.R.L. Estudo microbiológico da ação de extratos vegetais hidroalcoólicos sobre microorganismos bucais. 2011. 37p. Trabalho de Conclusão de Curso (Graduação - Área de Concentração em Odontologia). Universidade Estadual da Paraíba, Campina Grande.

LÚCIO, E.M.R.; Sharapin, N; França, H.S. Estudo de alcalóides de Pilocarpus pennatifolius Lemaire. Revista Brasileira de Farmacognosia, v. 12, p. 130-31, 2002.

MARQUES, F. J. Propagação sexuada e assexuada da Faveleira (Cnidoscolus Phyllacanthus (Müll. Arg.) Pax \& L. Hoffm.): Subsídios para o seu cultivo como lavoura xerófila. 2007. 112p. Dissertação (Mestrado - Área de concentração em Agronomia) - Universidade Federal Da Paraíba, Areia.

MATOS, F.J.A. Introdução à fitoquímica experimental. 2. ed. Fortaleza: Edições UFC, 1997. 141p.

MORAIS, S.M. et al. Ação antioxidante de chás e condimentos de grande consumo no Brasil. Revista Brasileira de Farmacognosia, v. 19, n. 1B, p. 315-20, 2009.

NACZK, M.; SHAHIDI, F.; Extraction and analysis of phenolics in food. Journal of Chromatography A, v. 1054, p. 95-11, 2004.

NÓBREGA, S. B. P. A faveleira (Cnidoscolus quercifolius) como fonte alternativa na alimentação humana e animal no Semi-Árido Paraibano. 2001. 145 f. Dissertação (Mestrado em Desenvolvimento e Meio Ambiente) - Universidade Federal da Paraíba, João Pessoa.

SALOMÉ, R.J. Análise fitoquímica dos princípios ativos, filantina, hipofilantina, e nirantina da espécie quebra-pedra (Phyllanthus amarus Schumach \& Thonn), sob condições de déficit hídrico. 2007. 94f. Dissertação (Mestrado - Área de concentração em Ciências). Universidade de São Paulo, Piracicaba.

SIMÕES, C.M.O. et al. Farmacognosia da planta ao medicamento. $6^{\mathrm{a}}$ ed. Porto Alegre/ 
Florianópolis: Editora UFRS/ UFSC, 2010. 1104p. SOUSA, C.M. et al. Fenóis totais e atividade antioxidante de cinco plantas medicinais. Química Nova, v. 30, p. 351-55, 2007.

SOUZA, O.V.S. et al. Estudo farmacognóstico de galhos de Vanillosmopsis erythropappa Schult.
Bip. - Asteraceaea. Revista Brasileira de Farmacognosia, v. 13, p. 50-53, 2003.

TEIXEIRA, L.N.; STRINGHETA, P.C.; OLIVEIRA, F.A. Comparação de métodos para quantificação de antocianinas. Revista Ceres, v. 55, n. 4, p. 297-04, 2008. 